\title{
NEFROMA MULTILOCULAR QUÍSTICO. PRESENTACIÓN DE UN CASO
}

\author{
A. AGUILAR RUIZ, A. TORRAMILANS LLUIS*, M. CASTELLS ESTEVE, \\ C. VARGAS BLASCO
}

Servicio de Urología. *Servicio de Radiología. Hospital San Llorenç de Viladecans. Barcelona.

Actas Urol Esp. 27 (9): 718-720, 2003

\section{RESUMEN}

NEFROMA MULTILOCULAR QUÍSTICO. PRESENTACIÓN DE UN CASO

Presentamos un nuevo caso de nefroma multilocular quístico y se realiza revisión de la literatura.

Ante una lesión quística compleja diagnosticada por T.C. aplicamos la clasificación de Bosniak. El nefroma multilocular se presenta en forma de lesión quística múltiple separada por tabiques fibrosos, con o sin calcificaciones, por lo que plantea el diagnóstico diferencial entre CCR y nefroma multiquístico. El diagnóstico definitivo es histológico.

PALABRAS CLAVE: Nefroma multilocular quístico. Enfermedad renal quística. Quiste multilocular benigno.

\section{ABSTRACT}

MULTILOCULAR CYSTIC NEPHROMA. A NEW CASE PRESENTATION

We present a new case of multilocular cystic nephroma, and a review of literature.

If C.T. diagnoses a cystic disease we apply the Bosniak classification. Multilocular cystic nephroma appears as a cystic disease, separately fibrous thin walls, with or without calcifications. We have to make a distinctive diagnosis between RCC and multilocular. Definitive diagnosis is always histological.

KEY WORDS: Multilocular cystic nephroma. Renal cystic disease. Benign multilocular.

$\mathrm{D}$ escrito en primera ocasión por Edmunds ${ }^{1}$ en 1892 que lo denominó adenoma quístico.

Las denominaciones que recibe esta entidad son: quiste renal multiloculado, riñón multiquístico segmentario, hamartoma quístico, nefroma quístico benigno y tumor de Perlman ${ }^{2,3}$.

\section{CASO CLÍNICO}

Mujer de 75 años de edad, con antecedentes de enfermedad pulmonar obstructiva, hipertensión arterial e hipercolesterolemia.

Consulta a nuestro servicio por el hallazgo ecográfico casual de una lesión renal.
Ecografía: lesión quística compleja, multiseptada, de contornos polilobulados, de $11 \mathrm{~cm}$ de diámetro y con calcificaciones puntiformes periféricas, que ocupa la práctica totalidad de dicho riñón.

T.C. abdomino-pélvico (Fig. 1): lesión renal izquierda de $11 \times 7 \mathrm{~cm}$ de diámetro, multiseptada y con calcificaciones puntiformes. Ausencia de adenopatías retroperitoneales.

Se plantea el diagnóstico diferencial entre nefroma multilocular quístico, como primera opción, y carcinoma de células renales quístico. 


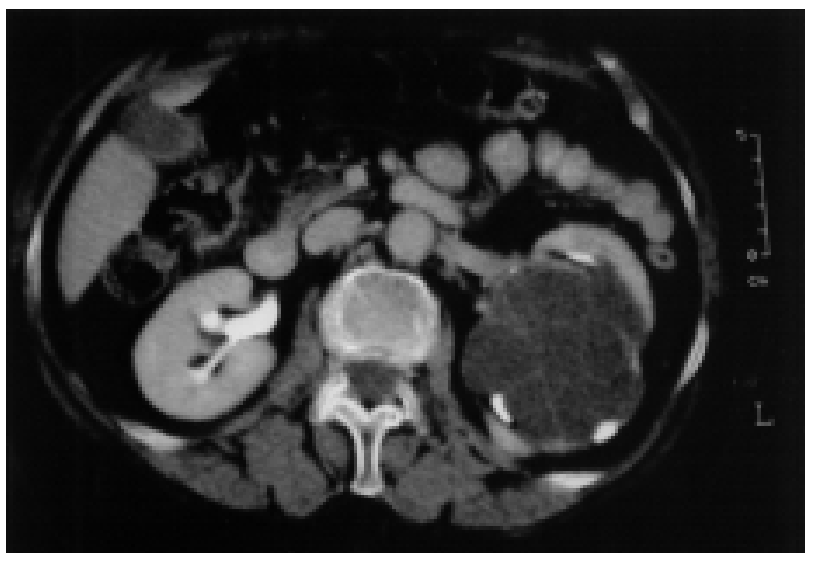

FIGURA 1. TC renal: lesión quistica de gran tamaño que se extiende hacia el seno renal, septada y con calcificaciones puntiformes.

Practicamos renograma isotópico con Tc-99m. Riñón izquierdo de inferior captación y funcionalismo, con imagen fría central que podría corresponder a lesión ocupante. Función del R.I.: 25\%.

Gammagrafía ósea: Sin alteraciones.

Con la orientación diagnóstica de lesión renal Bosniak III se decide intervención quirúrgica realizándose nefrectomía.

Informe anatomopatológico: Nefroma quístico multilocular, sin atipias.

\section{DISCUSIÓN}

Ante una lesión renal quística que no cumple criterios radiológicos de quiste simple debemos realizar TC abdominal, siendo muy útil aplicar la clasificación de Bosniak.

Clasificación de Bosniak ${ }^{11}$ :

- Clase I: corresponde al quiste simple.

- Clase II: quistes mínimamente complicados, presencia de septos finos y/o pequeñas calcificaciones, agrupaciones de quistes o quistes hiperdensos (+ $20 \mathrm{UH})$, siempre de tamaño inferior a $3 \mathrm{~cm}$.

- Clase IIF ("follow"): lesión quística, mínimamente complicada pero con algún signo "sospechoso" (mayor grosor de pared o calcificaciones groseras).

Actitud: seguimiento.

- Clase III: lesiones quísticas complejas (calcificaciones irregulares, margen irregular, septos gruesos).

Actitud: exploración quirúrgica. En el 50\% de los casos, aproximadamente, hallaremos una neoplasia maligna.
- Clase IV: son lesiones con componentes quísticos o necróticos y elementos sólidos. Actitud: intervención quirúrgica.

El nefroma quístico multilocular es una lesión renal congénita que no se transmite de forma genética ${ }^{4,5}$. Suele presentarse de forma unilateral y único, formado por múltiples quistes no comunicados, rodeados por una cápsula fibrosa gruesa que comprime el parénquima renal adyacente y con frecuencia se proyecta hacia la pelvis renal.

La edad de presentación en el 73\% de los casos es en pacientes menores de 4 años, en forma de masa palpable.

En pacientes mayores de 4 años el $89 \%$ son mujeres, teniendo dos picos entre 4-20 años y entre 40-60 años. En el adulto suele ser asintomático, presentándose como un hallazgo casual.

Con las técnicas de radiodiagnóstico no puede excluirse la malignidad, planteando el diagnóstico diferencial con el Tm de Wilms en niños y el CCR quístico en el adulto ${ }^{6,7}$.

Ecografía renal: imágenes quísticas, no comunicadas, separadas por tabiques fibrosos de estroma.

T.C. abdominal: objetivará una masa renal multiloculada. Los tabiques suelen ser delgados y no se realzan con el contraste.

La presencia de calcificaciones es de un $10 \%$, con un patrón inespecífico (central o periférico) $^{8-10}$.

La PAAF no está indicada ya que los quistes son independientes entre sí lo que precisaría de la punción individual de todos ellos.

Por todo ello, llegados a este punto no queda más opción que la exploración quirúrgica con cirugía parcial o total dependiendo de cada caso.

\section{REFERENCIAS}

1. MADAWELL JE, GOLDMAN SM, DAVIS CJ et al.: Multilocular cystic nephroma: a radiographic-pathologic correlation of 58 patients. Radiology 1983; 146 (2): 309-321.

2. DUNNICK N, SANDLER C, STEPHEN E et al.: Renal cystic disease. Textbook of uroradiology. Willians and Wilkins 1997; 2: 126-128.

3. Campbell. Benign multilocular cystic disease. Textbook of Urology 1997: 1786-1789. 
4. ROBBEN A.: Multilocular cystic nephroma. Jour Belgeum Radiology 1998; 81 (5): 247.

5. MADRID FJ y cols.: Nefroma quístico multilocular. Arch Esp Urologia 1998; 51 (5): 493-498.

6. CHARBONEAU JW, HATTERY R, ERNEST E et al.: Spectrum of sonographic findings in 125 renal masses other tan benign simple cyst. AJR 1983; 140 (1): 87-94.

7. HARTMAN DS et al.: The multiloculated renal mass: considerations and differential features. Radiographics 1987; 7 (1): 29-52.

8. LEE S, STANLEY, HEYKEN.: Body CT and MRI Editorial Marban 1999: 370-372.

9. GARRET et al.: Multilocular cystic nephroma. Radiological Clinics of North America 1987; 38 (1) 55-57.
10. GONZÁLEZ-CRUSSI y cols.: Cystic nephroma. Urology 1982; 20 (1): 88-93.

11. POLLACK, MC CLENNAN.: Textbook "Clinical urography" $2^{\circ}$ edition; 1: 484-487.

Dr. A. Aguilar Ruiz

Servicio de Urología

Hospital de Viladecans

Avda. Gava, 38

08840 Viladecans (Barcelona)

(Trabajo recibido el 10 enero de 2003) 